\title{
Reversible Covalent Patterning of Self-Assembled Monolayers on Gold and Silicon Oxide Surfaces
}

\author{
Dorota I. Rozkiewicz, Bart Jan Ravoo*, David N. Reinhoudt* \\ Laboratory of Supramolecular Chemistry and Technology, MESA ${ }^{+}$Institute for Nanotechnology. \\ University of Twente, P. O. Box 217, 7500 AE Enschede, The Netherlands.
}

E-mail: $\underline{\text { smct@tnw.utwente.nl }}$

\section{SUPPORTING INFORMATION}

\section{Contact Angle Measurements.}
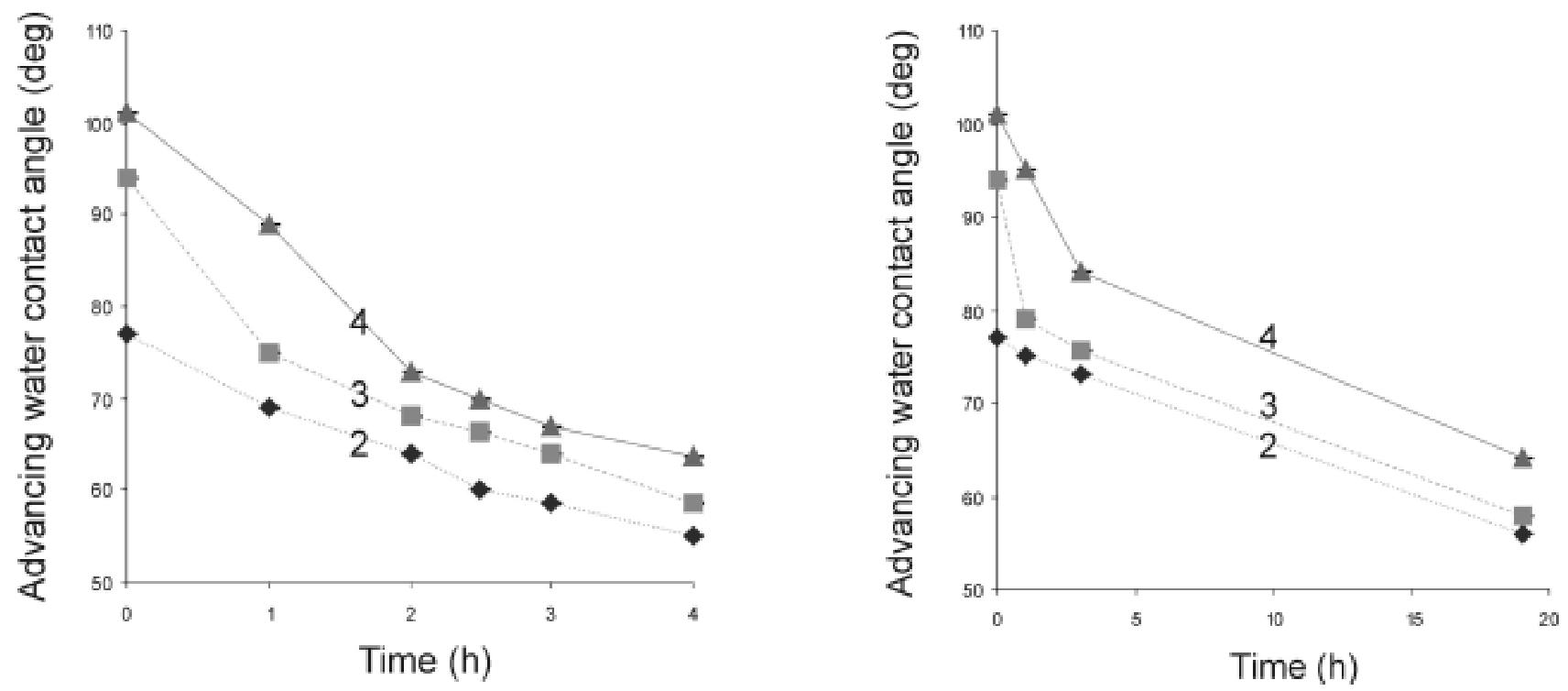

Figure 1. Advancing water contact angle after hydrolysis of imines 2, 3, 4 on gold substrates at $100{ }^{\circ} \mathrm{C}$ (left graph) and $40{ }^{\circ} \mathrm{C}$ (right graph).

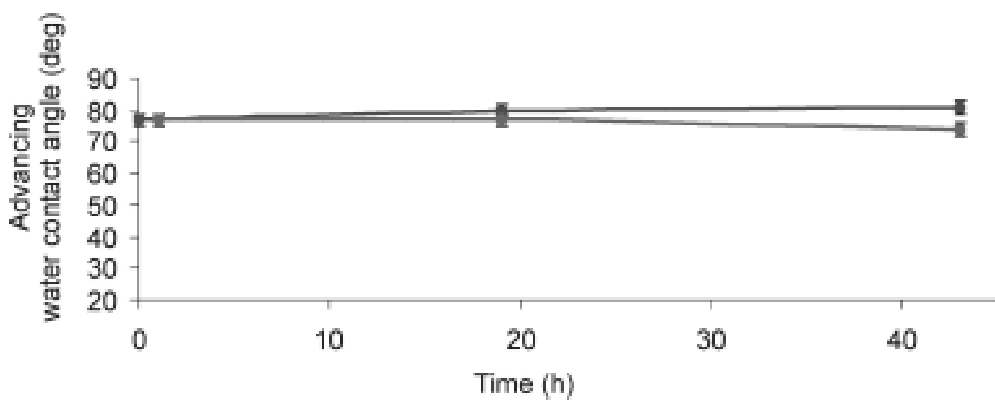

Figure 2. Advancing water contact angles of imine 2 SAMs as a function of the time. Control experiment. 


\section{Heterogeneous Electron Transfer Measurements.}

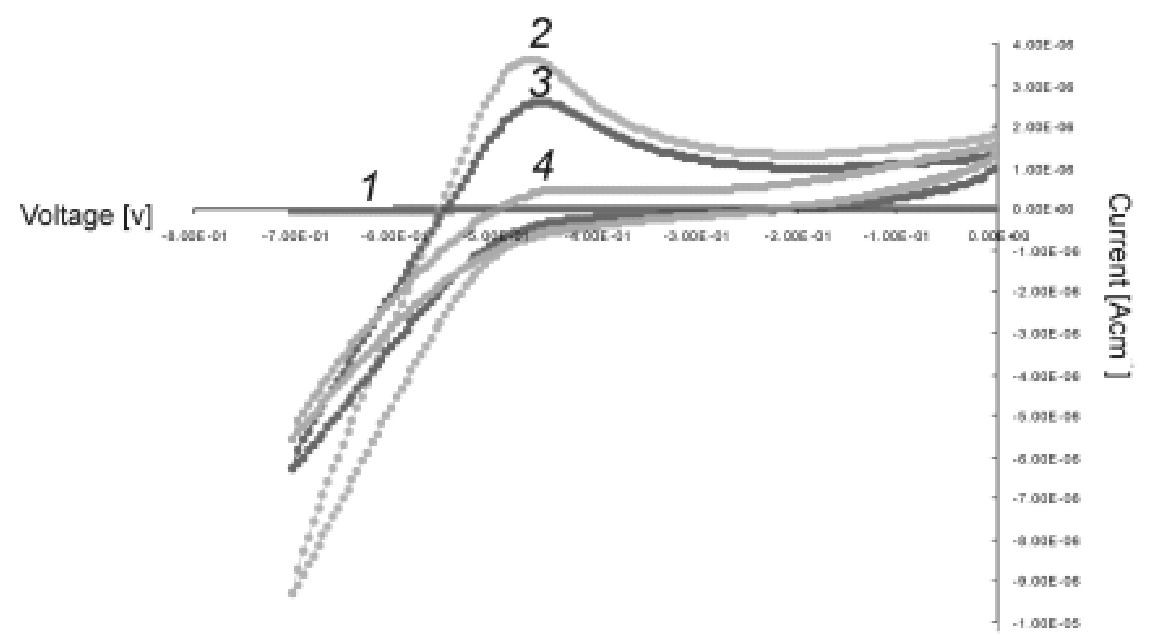

Figure 3. Cyclic voltammogram for heterogeneous electron transfer of $\mathbf{1}$ and imine 2, 3, $\mathbf{4}$ monolayer.

\section{Printing Amines on Aldehyde-terminated Monolayer. Control Experiment.}

XPS measurements were conducted to investigate a transfer of any material from SEBS stamp that could possibly give unwanted pattern without ink transfer (Figure 4).
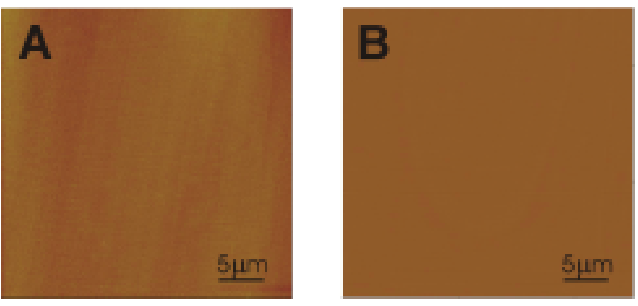

Figure 4. AFM height (A) and friction (B) image of control experiment.

To show no transfer of material from the SEBS stamp occurs, a flat (without any pattern) stamp was brought in to a contact with the gold substrate for $1 \mathrm{~min}$. The surface scans of both blank and control sample look almost the same. High resolution scan of $\mathrm{C} 1 \mathrm{~s}$ and $\mathrm{O}$ 1s (Figure 5) also shows no significant difference between concentration of carbon and oxygen on the surface, which might suggest that there is no transfer of unwanted low molecular weight molecules from the stamp and the only transfer could be possibly coming from inking the stamp. 


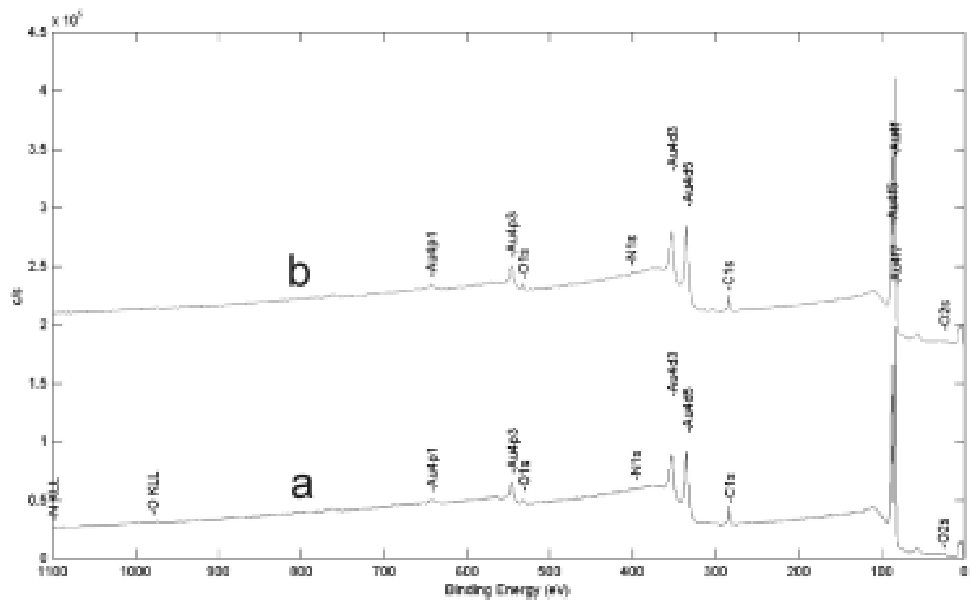

Figure 5. XPS surface scan of control sample, a) blank sample; b) sample after 1 min contact with flat SEBS stamp without ink.
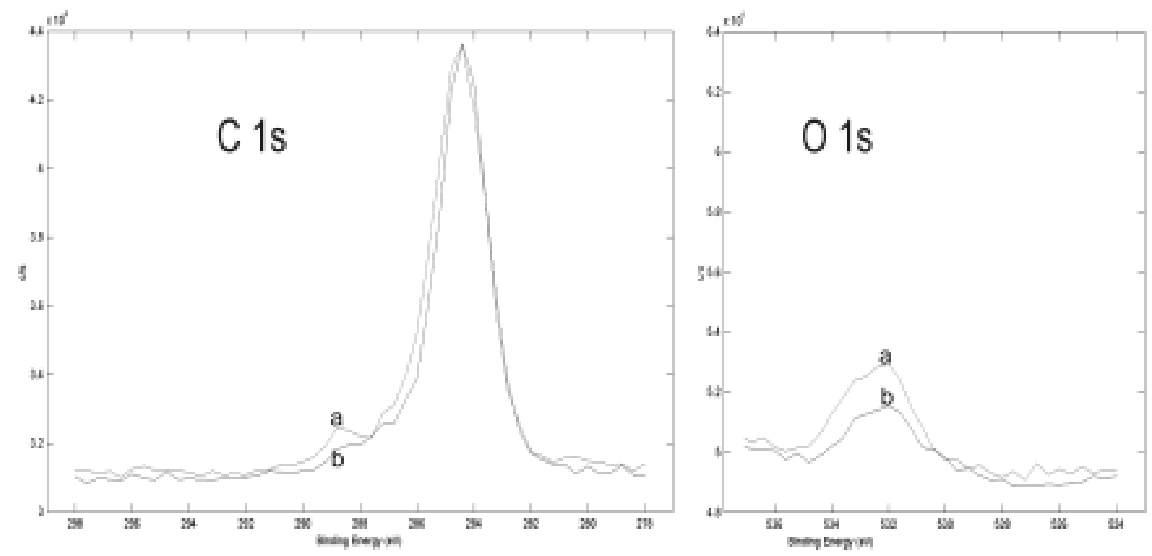

Figure 6. High resolution XPS scans of $\mathrm{C}$ 1s (left) and O 1s (right) regions of control (blank gold substrate, blue line) and substrates that was in contact with SEBS stamp (red line).

\begin{tabular}{ccccc}
\hline Surface & $\mathrm{N} / \mathrm{C}$ & $\mathrm{C} / \mathrm{Au}$ & $\mathrm{S} / \mathrm{C}$ & $\mathrm{O} / \mathrm{C}$ \\
\hline Control & 0 & 0.99 & 0 & 0 \\
$\begin{array}{c}\text { Au+SEBS } \\
\text { min contact }\end{array}$ & 0 & 1.12 & 0 & 0
\end{tabular}

Table 1. Atomic ratios of elements N, S, O, C and Au on control surface (bare gold) and surface that was for $1 \mathrm{~min}$ contact with SEBS stamp. 